\section{Response to: 'Association of proton pump inhibitors with fracture risk in patients with rheumatoid arthritis' by Sugiyama}

We appreciate the interest shown by Dr Sugiyama ${ }^{1}$ concerning our recent study on medications associated with fracture risk in patients with rheumatoid arthritis (RA). ${ }^{2} \mathrm{He}$ emphasises the lack of association between proton pump inhibitor (PPI) use and fracture risk in patients with RA, which has been a conflicting issue for the general population. We agree that the previous studies showing an increased fracture risk with PPIs in the general population may be confounded by the indication as it is known that PPI use is mostly accompanied with other comorbidities or use of other medications, which may already heighten the fracture risk. In a disease state like RA, where the fracture risk is already increased, we did not find an increased fracture risk with PPIs after adjustment for several other factors for fractures. However, we have to indicate that we did not evaluate different PPI doses and types, which may have different risk estimates. Although PPIs are very effective in the prevention of gastrointestinal bleeding with certain medications, we would like to remind that they may be associated with other adverse events. PPIs have shown to be associated with increased risk of community-acquired pneumonia, ${ }^{3}$ and Clostridioides difficile and other enteric infections ${ }^{45}$ in the general population, although confounding bias may still be an issue in those studies. Moreover, it has been suggested that PPIs may have a role in antiplatelet-clopidogrel- failure and might be associated with worse cardiovascular (CV) outcomes in patients with coronary artery disease. ${ }^{6}$ Therefore, the potential risk-benefit ratio of PPIs should be weighed carefully when prescribing these medications particularly in RA, where the use of nonsteroidal anti-inflammatory drugs, glucocorticoids or antiplatelets are quite common and the risks of infections, $\mathrm{CV}$ disease and fracture are already heightened. Future studies examining both risks and benefits of PPIs with identification of numbers needed to treat and harm for prevention of gastrointestinal bleeding and development of any of the adverse events, respectively, would be more helpful in clinical decision making.

To conclude, despite the data favouring no fracture risk increase with PPIs, we believe that regular review of medications and deprescription of unnecessary ones, including PPIs, is critical in RA as polypharmacy and multicomorbidity predispose patients to potential drug interactions and other adverse events.

\section{Gulsen Ozen, ${ }^{1}$ Kaleb Michaud ${ }^{1,2}$}

${ }^{1}$ University of Nebraska Medical Center, Omaha, Nebraska, USA

${ }^{2}$ FORWARD, The National Databank for Rheumatic Diseases, Wichita, Kansas, USA

Correspondence to Dr Kaleb Michaud, FORWARD, The National Databank for Rheumatic Diseases, Wichita, KS 67214, USA; kmichaud@unmc.edu

Correction notice This article has been corrected since it published Online First. The author name has been corrected in the content of the correspondence.

Competing interests None declared.

Patient consent for publication Not required.

Provenance and peer review Commissioned; internally peer reviewed.

(C) Author(s) (or their employer(s)) 2020. No commercial re-use. See rights and permissions. Published by BMJ.

$$
\text { A) Check for updates }
$$

To cite Ozen G, Michaud K. Ann Rheum Dis 2020;79:e111.

Received 23 May 2019

Accepted 25 May 2019

Published Online First 31 May 2019

\section{Linked}

- http://dx.doi.org/10.1136/annrheumdis-2019-215747

Ann Rheum Dis 2020;79:e111. doi:10.1136/annrheumdis-2019-215775

\section{ORCID iD}

Kaleb Michaud http://orcid.org/0000-0002-5350-3934

\section{REFERENCES}

1 Sugiyama T. Association of proton pump inhibitors with fracture risk in patients with rheumatoid arthritis. Ann Rheum Dis 2020;79:e110.

2 Ozen G, Pedro S, Wolfe F, et al. Medications associated with fracture risk in patients with rheumatoid arthritis. Ann Rheum Dis 2019;78:1041-7.

3 Lambert AA, Lam JO, Paik JJ, et al. Risk of community-acquired pneumonia with outpatient proton-pump inhibitor therapy: a systematic review and meta-analysis. PLOS One 2015:10:e0128004.

4 HHW, Chen YT, Shih CJ, et al. Association between recent use of proton pump inhibitors and nontyphoid salmonellosis: a nested case-control study. Clin Infect Dis 2014;59:1554-8.

5 Kwok CS, Arthur AK, Anibueze $\mathrm{Cl}$, et al. Risk of Clostridium difficile infection with acid suppressing drugs and antibiotics: meta-analysis. Am J Gastroenterol 2012;107:1011-9.

6 Sherwood MW, Melloni C, Jones WS, et al. Individual proton pump inhibitors and outcomes in patients with coronary artery disease on dual antiplatelet therapy: a systematic review. J Am Heart Assoc 2015;4. 